\title{
THE COMBINED EFFECT OF CORTISONE ACETATE AND DESOXYCORTICOSTERONE ACETATE IN ADRENAL- ECTOMIZED RATS ON A LOW SODIUM DIET ${ }^{1}$
}

\author{
BY ABBIE I. KNOWLTON, EMILY N. LOEB, HERBERT C. STOERK, AND \\ WILLIAM C. MOHLER WITH THE TECHNICAL ASSISTANCE OF FERN \\ BROOK, DOROTHY WENDELLE, AND EMILY BIDWELL \\ (From the Department of Medicine, College of Physicians and Surgeons, Columbia University, \\ and the Presbyterian Hospital, New York; and the Merck Institute for \\ Therapeutic Research, Rahway, N. J.)
}

(Submitted for publication July 1, 1953; accepted July 13, 1953)

In a previous report the authors have described the response of young adrenalectomized rats to desoxycorticosterone acetate (DCA) and to cortisone acetate (CA) when maintained on a diet severely restricted in sodium content (1). Daily injections of $2.5 \mathrm{mg}$. of DCA resulted in progressive weight gain and maintenance of normal blood pressure, while similar doses of CA were accompanied by rapid weight loss and arterial hypertension. With both steroids terminal serum sodium values were within normal range.

The present experiments describe the results obtained over a wide range of dosages of $\mathrm{DCA}^{2}$ and $\mathrm{CA},{ }^{8}$ given singly and in varying combinations, and were undertaken in an attempt to determine to what extent the individual action of each steroid was modified by concomitant administration of the other.

\section{METHODS}

Nine separate experiments were conducted over the period of a year and a half, employing a total of 425 female rats of the Sprague-Dawley strain. The animals were purchased at a weight of 90 to $100 \mathrm{Gm}$.4 The rats were housed in individual cages and, after a one or two week control period, were adrenalectomized under ether anesthesia. Sodium restriction was instituted in all groups immediately postoperatively with the exception

1 This research has been supported by a grant from the U. S. Public Health Service, National Institutes of Health (H-1302) and the Albert and Mary Lasker Foundation.

2 DCA, desoxycorticosterone acetate, was supplied through the generosity of Dr. Kenneth Thompson of Organon, Inc., Orange, N. J.

$3 \mathrm{CA}$, cortisone acetate, was made available through the kindness of Merck and Company, Rahway, New Jersey.

4 From the Holtzman-Rolssmeyer Co., Madison, Wisconsin. of one group of 19 control rats, in which a four-day recovery period on a high salt regimen (i.e., 1.7 per cent $\mathrm{NaCl}$ in the diet, plus 0.9 per cent saline as drinking water) intervened between adrenalectomy and the introduction of the experimental regimen. The details of the low sodium diet have been reported previously (1). Analyses on three occasions in the past year, since the substitution of low sodium yeast 5 for the debittered form, have yielded $0.36,0.35$, and $0.40 \mathrm{mEq}$. of sodium per $100 \mathrm{Gm}$. of diet. Immediately postoperatively, sodium restriction was instituted and at the same time injections of the steroid to be tested were started, and repeated daily. The varying doses of DCA were dissolved or suspended in $0.25 \mathrm{ml}$. of sesame oil. The CA was suspended in normal saline or in the following vehicle: Tween $80,0.4$ per cent; sodium carboxymethylcellulose, 0.5 per cent; benzyl alcohol, 1.5 per cent; and sodium chloride, 0.9 per cent. The varying doses of CA were given in a total volume of $0.25 \mathrm{ml}$., except in the groups receiving $2.5 \mathrm{mg}$., in which $0.5 \mathrm{ml}$. were given. Weights were recorded daily. Blood pressures, using the microphonic manometer method described by Friedman and Freed (2) were determined prior to adrenalectomy and again four to eight days after the institution of the experimental regimen. The animals were sacrificed at the end of six to ten days by exsanguination from the incised heart under nembutal anesthesia. Serum this collected from individual animals was pooled according to group and analyzed for sodium content.

\section{RESULTS}

The results are set forth in the three accompanying tables.

Table I: Changes in body weight. The two groups of untreated adrenalectomized rats sustained weight losses of 16 and $25 \mathrm{Gm}$. during the experimental period. In the groups receiving DCA alone, doses of as little as $0.005 \mathrm{mg}$. resulted in less weight loss than in untreated animals. With increasing amounts of DCA there

B Bowman Food Yeast, furnished through the courtesy of Charles Bowman \& Co., New York. 
obtained a straight line correlation between the log dose of this steroid and the overall weight change, until the dosage of $2.5 \mathrm{mg}$. was reached. Whether the slow rate of gain in this group of animals was the result of conditions peculiar to that one experiment or whether it constitutes a consistent finding requires additional data. In groups of rats receiving varying doses of CA alone no dosage level was encountered which prevented weight loss, and at the two highest dosage schedules employed (1.25 and $2.5 \mathrm{mg}$. daily) the rats lost weight even more rapidly than the untreated control groups. When the two steroids were given in combination, the growth-promoting effects of DCA predominated until the daily dose of $\mathrm{CA}$ was in excess of $0.32 \mathrm{mg}$. At the dosage level of $1.25 \mathrm{mg}$. of $\mathrm{CA}$, no weight gain was seen even when large doses of DCA were given concomitantly, while at the level of $2.5 \mathrm{mg}$. the CA marked weight losses occurred despite DCA.
Table II: Blood pressure. A progressive fall in blood pressure to unobtainable levels ensued in the untreated adrenalectomized rats when subjected to the sodium restricted conditions of this experiment. In the groups given DCA alone the blood pressure was maintained at low normal to normal levels. Daily doses of $0.08 \mathrm{mg}$. and above were perhaps more effective in this regard, but even in the groups receiving only $0.005 \mathrm{mg}$. daily some blood pressure sustaining action was apparent. At no dosage level was hypertension seen in the animals receiving DCA alone. In the groups given $\mathrm{CA}$, blood pressure was sustained less consistently than with DCA at the lower dosage levels. However, as the dosage was increased the blood pressure rose and in the groups receiving $2.5 \mathrm{mg}$. daily definite hypertension was evident as early as six days after the institution of the regimen. When combinations of DCA and $\mathrm{CA}$ were given, the hypertensive action of the

TABLE I

Weight change of groups of adrenalectomized rats after six days of sodium restriction and daily injections of $D C A$ and $C A$, singly and in combination*

(Grams)

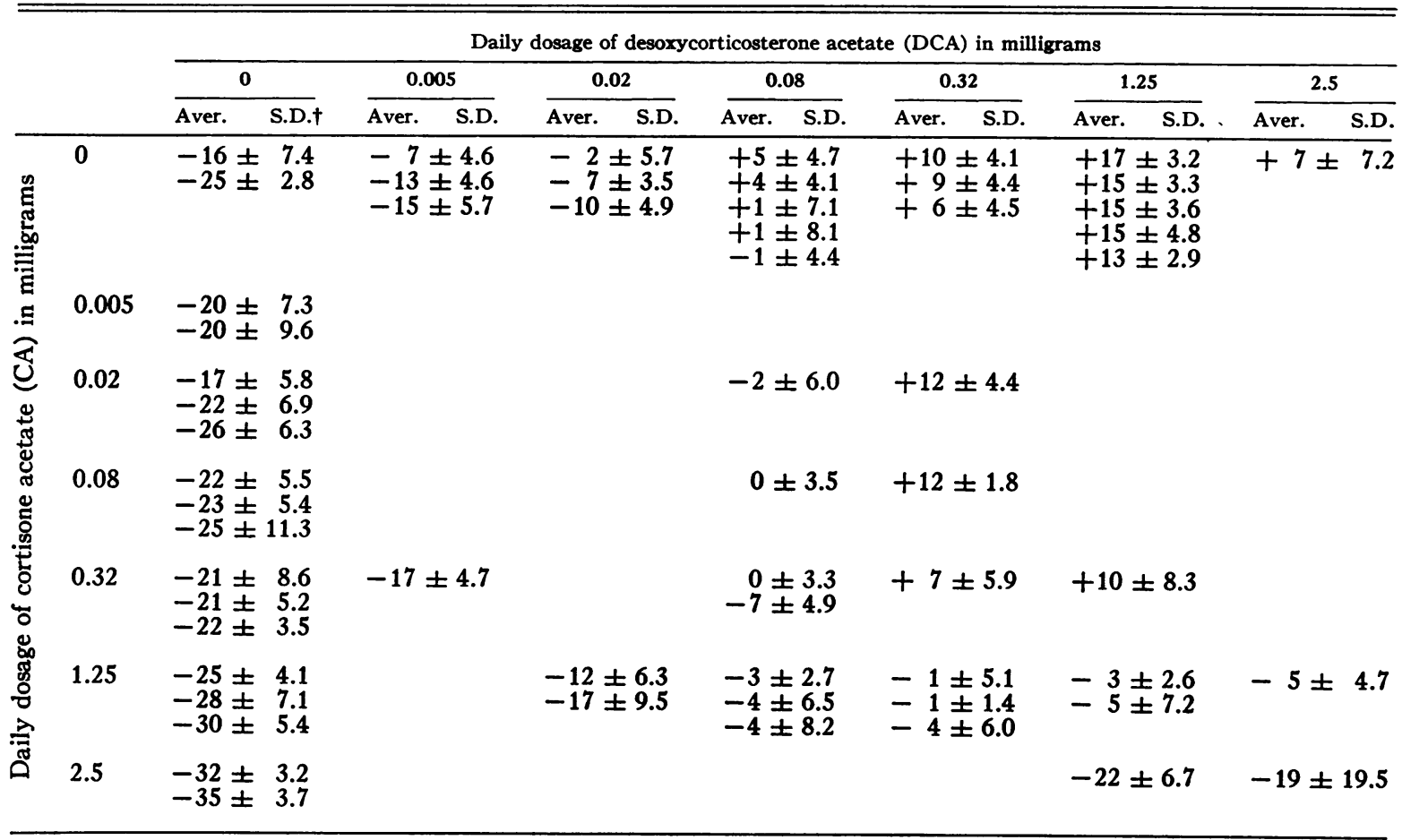

* Each value represents the average weight change of 6 to 19 individual rats. Where two or more values are recorded for one dosage schedule, each represents the result of a separate experiment.

†S.D. $=\sqrt{\sum \frac{(x-n)^{2}}{n}}$. 
TABLE II

Blood pressure readings on groups of adrenalectomized rats after four to eight days of sodium restriction and daily injections of $D C A$ and $C A$, singly and in combination*

$(\mathrm{mm} . \mathrm{Hg})$

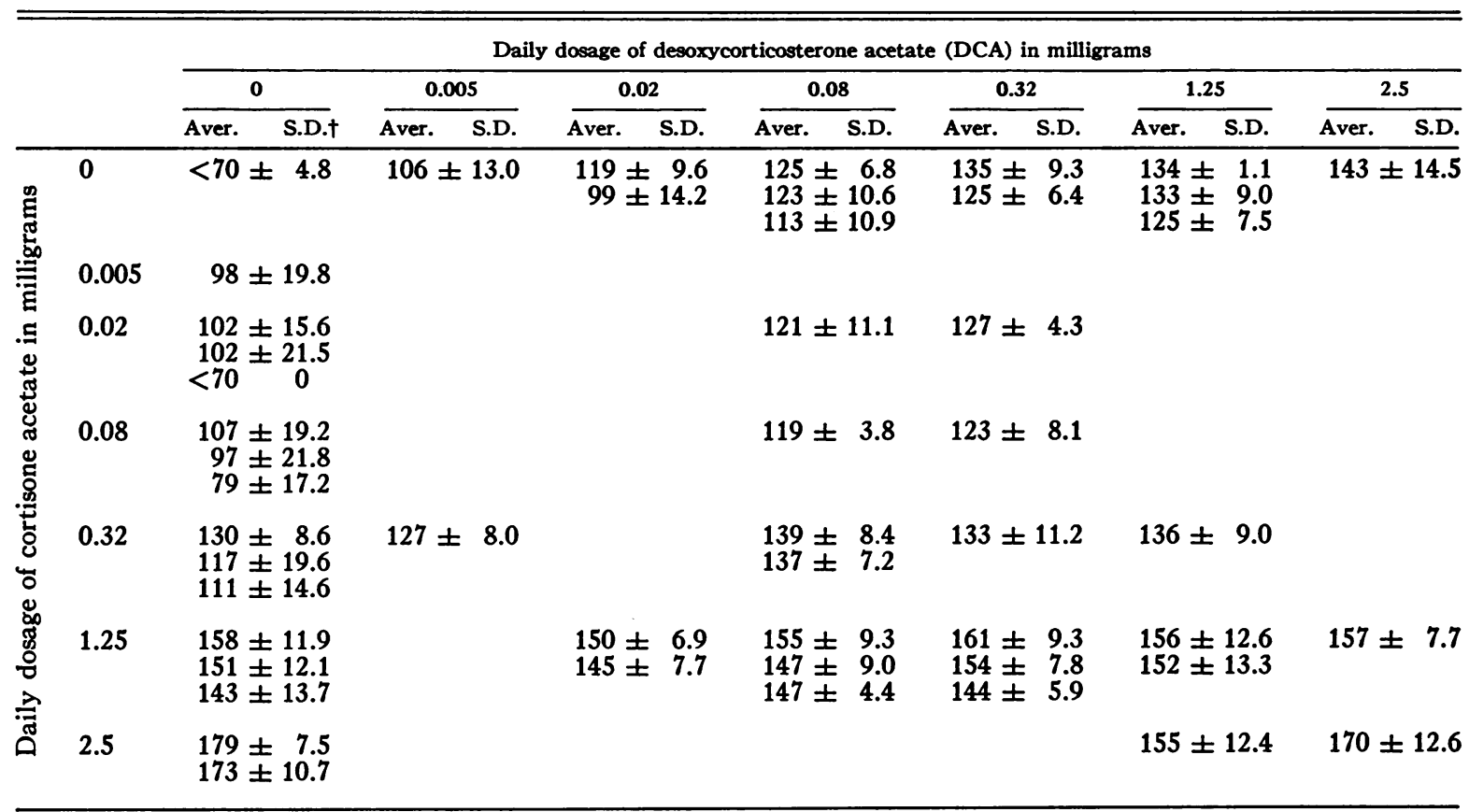

* Each value represents the average of blood pressure readings on a group of 6 to 10 individual rats. Where two or more values are recorded for one dosage schedule, each represents the result of a separate experiment.

†S.D. $=\sqrt{\sum \frac{(x-n)^{2}}{n}}$.

latter was not interfered with over a wide range of DCA dosage.

Table III: Terminal serum sodium values on pooled sera. In the untreated adrenalectomized rats a sharp reduction in the serum sodium was observed consistently. In the groups given DCA alone, the serum sodium concentration rose progressively as the dosage of the steroid was increased, to reach normal levels in the range of 0.08 to $0.32 \mathrm{mg}$. daily. Additional increases in dosage were without further effect upon the serum sodium. In the groups receiving CA alone no effect upon serum sodium was evident until a daily dosage of $1.25 \mathrm{mg}$. was reached, when low normal to normal values were obtained. In the hypertensive rats on $2.5 \mathrm{mg}$. daily, sodium values were, as known previously, entirely normal. In groups given a combination of the two steroids the concentration of sodium paralleled the dosage of DCA, except in the lower dosage range, where the values suggest an additive effect, although the data are too meager to permit a definitive statement.

\section{DISCUSSION}

At the outset of the currently reported experiments it seemed that the effect of desoxycorticosterone acetate (DCA) upon growth in the young adrenalectomized rat (3) might be used, along with observations upon the serum sodium values, as a tool for developing a simple assay method for DCA-like activity. The consistency of the response as seen in the above experiments proves this to be a useful technique. Before applying this assay to biological materials it was essential to know to what extent the possible presence of cortisone-like steroids, with their known suppressive effects upon growth might interfere with the characteristic DCA response. Ingle (4) had reported that no inhibition of growth was evident until daily doses of $5 \mathrm{mg}$. of cortisone acetate (CA) were given concomitantly with the 
TABLE III

Terminal serum sodium concentrations in groups of adrenalectomized rats after six to ten days of sodium restriction and daily injections of $D C A$ and $C A$, singly and in combination* (mEq. per liter)

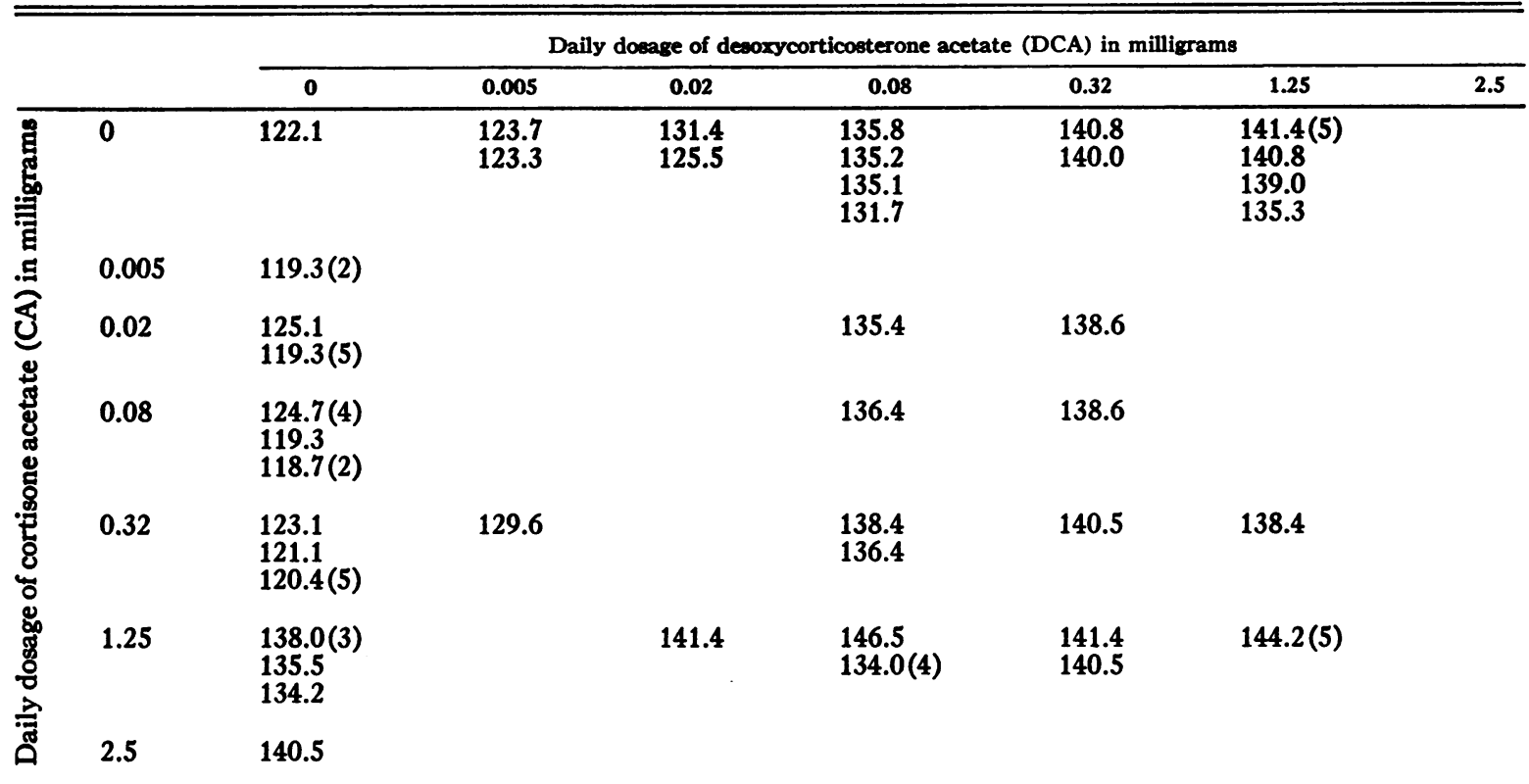

* Each value represents the sodium concentration in the pooled sera of 6 to 8 individual rats. When less than this number were included in a pool, the figures in parentheses indicate the number sampled. Where two or more values are recorded on one dosage schedule, each represents the result of a separate experiment.

DCA. However, under the sodium restricted conditions of the present study the addition of CA in doses exceeding $0.32 \mathrm{mg}$. daily regularly inhibited the anticipated growth response to DCA. At levels of $\mathrm{CA}$ in excess of $1.25 \mathrm{mg}$. this steroid could be detected by the appearance of hypertension, but there may well exist a considerable range in which sufficient CA could be present to suppress growth and yet be insufficient to raise the blood pressure. Hence, this will not provide a useful assay method for DCA when CA-like materials are present unless the amount of the latter substances can be determined separately.

The data presented, on the effects of DCA and of CA singly and in combination over a wide range of dosage upon body weight, blood pressure and serum sodium concentration, serve to emphasize the wide biological differences between these two steroids. With gradually increasing doses of DCA, the adrenalectomized animals pass from a state of obvious adrenal insufficiency to one more nearly approximating normal, with improvement first in blood pressure maintenance, then increase in serum sodium to normal, and then finally normal growth. In striking contrast, with increasing doses of $\mathrm{CA}$, the groups emerge from frank adrenal insufficiency with normal serum sodium concentrations but with mounting hypertension and rapidly progressive emaciation. When dosages of CA sufficient to produce the latter two manifestations are given, large doses of DCA are ineffective in preventing their appearance.

\section{SUMMARY}

Observations are presented on the effects of desoxycorticosterone acetate (DCA) and cortisone acetate (CA) given separately and in combination upon growth, blood pressure and serum sodium of adrenalectomized rats on a sodium restricted intake.

With doses ranging from 5 gamma to $1.25 \mathrm{mg}$. daily of DCA, a consistent straight line relationship was obtained between the log dose of the steroid and body growth. Some effect upon blood pressure maintenance was demonstrable with doses as low as $\mathbf{5}$ gamma, though at no level was 
hypertension seen. An effect upon serum sodium concentration was first noted with doses as low as $\mathbf{2 0}$ gamma and above $\mathbf{8 0}$ gamma normal values obtained.

With doses ranging from 5 gamma to $2.5 \mathrm{mg}$. daily cortisone acetate (CA) the rats consistently lost weight and hypertension appeared at the highest dosage levels. No effect upon serum sodium concentration was evident until dosages of $1.25 \mathrm{mg}$. daily were given.

With combinations of the two steroids, the growth-promoting effects of DCA were inhibited by doses of CA in excess of $0.32 \mathrm{mg}$. daily.- The presence of DCA did not interfere with the development of $\mathrm{CA}$-induced hypertension.

\section{REFERENCES}

1. Knowlton, A. I., Loeb, E. N., Stoerk, H. C., White, J. P., and Heffernan, J. F., Induction of arterial hypertension in normal and adrenalectomized rats given cortisone acetate. J. Exper. Med., 1952, 96, 187.

2. Friedman, M., and Freed, S. C., Microphonic manometer for indirect determination of systolic blood pressure in the rat. Proc. Soc. Exper. Biol. \& Med., 1949, 70, 670.

3. Grollman, A., Further observations on replacement therapy in experimental adrenal cortical insufficiency with desoxycorticosterone acetate and sodium chloride. Endocrinology, 1941, 29, 862.

4. Ingle, D. J., The effect of two cortin-like compounds upon the body weight and work performance of adrenalectomized rats. Endocrinology, 1940, 27, 297. 